IP Periodica Polytechnica

Architecture

47(2), pp. 94-98, 2016

DOI: $10.3311 /$ PPar. 10190

Creative Commons Attribution (i)

RESEARCH ARTICLE

\section{BIM to BEM as Teaching Methodology to Support Sustainable Construction Decisions}

\author{
Pedro Santiago ${ }^{1 *}$
}

Received 19 October 2016; accepted 28 November 2016

\begin{abstract}
Sustainability is a major issue in the built environment. Each generation of architects has a responsibility towards building a more efficient and balanced world. Universities have the task of preparing new professionals for global demands. As far as sustainability is concerned, a practical, visible approach has a greater and more rapid impact on the student. The use of BIM technologies allows real-time experience, providing a real feel sensation and producing faster results. This methodological approach and its results are the focus of this paper, referring to BEM with Archicad and Ecodesigner star as tools to evaluate thermal behaviour and the material impact of the proposed designs.
\end{abstract}

\section{Keywords}

sustainable construction, BEM, LCA, BIM
${ }^{1}$ Arquitectura e Urbanismo,

Faculdade de Ciência e Tecnologia,

Universidade Fernando Pessoa

Praça 9 de Abril, 349 | 4249-004 Porto

*Corresponding author, e-mail: psantiag@ufp.edu.pt

\section{Introduction}

BIM technology, as a design tool, is becoming the construction industry standard. The teaching of this software is imperative in universities as new designers, architects and engineers will be demanded to use them at a professional level in every stage of the building process. From the very early design stage up to the management of the building during its use cycle, BIM technology presents advantages by allowing data-based workflows and data-driven design decisions.

"Utilising BIM models in environmental simulations can help architects and engineers deliver a better building by supporting energy performance decisions at various stages of the design process." (Kuskilis, 2011)

In this article, the class of Construção Sustentável (sustainable construction) is going to be presented as a case study of the implementation and transition of BIM (building information modelling) to BEM (building energy modelling), along with the respective results, as environmental awareness during the design stage.

\section{Overview}

The class of Construção Sustentável has been lectured since 2010, with the objective of teaching students the main elements of sustainable construction through the buildings energy performance and life-cycle impact, presenting a holistic approach towards environmental issues.

The course content is divided into four major parts: 1) theoretical fundaments; 2) how to use BIM models to perform building energy analysis and material impact; 3) develop a quantitative understanding concerning how building design and construction systems affect the energy performance and environmental impact, and 4) improve a building's energy and material impact on the environment. Establishing and understanding the relationship between design, construction, energy consumption and material impact is crucial if students are to think critically about how a building's design and construction impacts the building's sustainability.

The course structure is based on buildings' energy efficiency referring to both passive and active systems, as well as the impact of materials and mechanical systems on the 


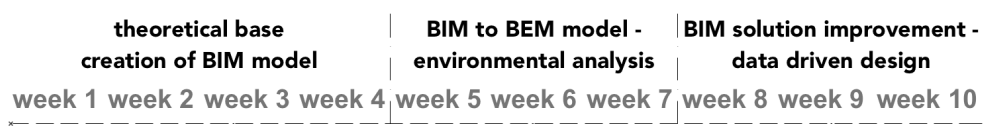

Fig. 1 Timeline of the course (author)

previous method workflow

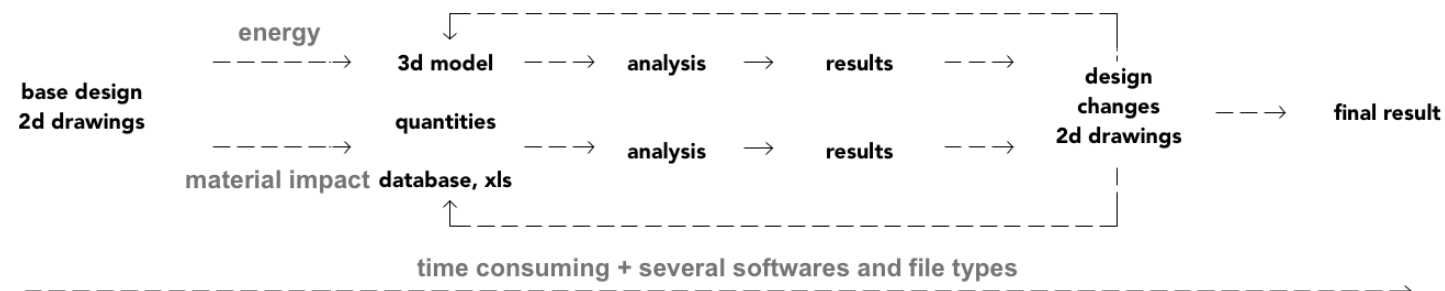

Fig. 2 Pre-BIM workflow (author)

environment. The first classes consist of the theoretical basis of these themes and topics, to structure the student's ability to implement the solutions and interpret the results.

After this component is completed, some case studies are analysed as examples; these are always accompanied by results, so data is present at all stages of the process, establishing the bridge between theory and application. The case studies cover a wide range of architectural examples from vernacular to prototypes. When this framework is concluded, students are asked to solve a practical exercise that consists of improving the energy performance and material impact of a future or existing building of their choice, as long as it fulfils certain requirements. The building must be residential, freestanding and suited for a single family.

Within these boundaries, the student can combine the theoretical component with a practical exercise. They can test the methodology, consisting of four steps based on the Lysen's Trias Energetica (Lysen, 1996), complemented with material impact and using $\mathrm{CO} 2$ as the common evaluation unit both energy as well as material wise:

1. Reduce the overall energy demand of the building implementing passive systems - no $\mathrm{CO} 2$

2. Reduce the overall environmental impact of building materials - embedded $\mathrm{CO} 2$

3. Supply the energy demand with renewable energy - no $\mathrm{CO} 2$

4. Supply the remaining part with efficient use of fossil fuel - emitted CO2

The complexity and size will not differ too much from the various cases presented; nevertheless, maintaining diversity increases interest and prevents plagiarism. Students have the opportunity to learn from their work and their fellow colleagues' case studies.

\section{BIM to BEM, methodology and workflow}

The pre-BIM workflow involved a complex process of working with $2 \mathrm{D}$ drawings as a base and changing the work environment and software as energy and material impacts were analysed. Every optimisation and design decision involved going through this process as many times as needed. This was revealed to be time-consuming and complex, as errors and omissions were constantly occurring and difficult to detect.

The proposed BIM workflow presented huge advantages as far as simplifying the process, time involved and user friendliness of interfaces as it is all integrated.

The software chosen for this class and assignment is Archicad with its energy evaluation add-on Ecodesigner Star. At this stage of their courses, students are already proficient at using the BIM software to create models of the buildings. The technical details of how to evolve the model from BIM to BEM and using other features such as energy and $\mathrm{CO} 2$ embedded in the construction materials were taught using in-class tutorials, exercises and assignments.

Students create a very detailed BIM model so that the resulting data is as accurate as possible, thoroughly defining construction materials, applying all the respective compositions to construction elements and modelling all the details.

The materials database contains information that is crucial to the purpose of the exercise such as thermal conductivity, density, heat capacity, embodied energy and embodied carbon. These parameters and values will be crucial to the accurate result, so whenever applying and creating a new material they cannot be neglected.

Construction systems will, therefore, originate new conjugated values of thermal conductivity and embodied carbon and energy, depending on the thickness and surface area, corresponding to the amount of each material used in the building.

The only external information consists of databases of material characteristics and weather files. All the workflow is processed inside the BIM software interface. 


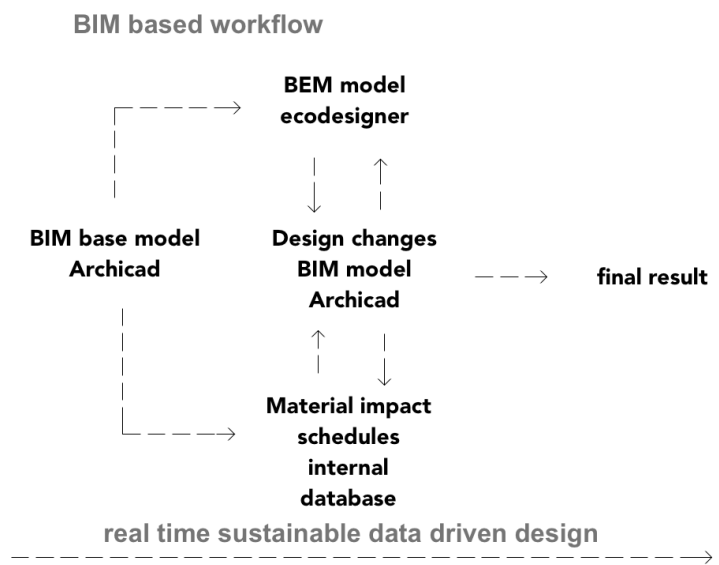

Fig. 3 BIM workflow (author)

The methodology and analysis of the information provided allow the student to create awareness of the potential of natural systems such as passive heating and natural ventilation, thus putting in practice the theoretical principles given in previous classes. This analysis is crucial to the rest of the exercise as it determines the natural efficiency of the building, which is optimised before the next stage. Daily interior temperature charts are extracted without building services applied for analysis.

At this stage, the material aspects of the building play a major role because of thermal insulation and heat capacity. Lists and schedules are created, and for the first time, $\mathrm{CO} 2$ appears as a measuring unit.

Energy issues are introduced in steps 3 and 4, and the measuring unit remains, allowing a straightforward comparison. The resulting analysis for this exercise considered in $\mathrm{CO} 2$, both from fossil fuel emissions and materially embodied carbon, is generated from the energy evaluation simulation document in the form of a report. From this can be extracted the data concerning energy issues, and from a scheduled list of all the materials used in the model, the amount of embodied carbon by the material.

This allows the calculation of the impact the building has on the environment, as well as estimate its life cycle impact and analysis for a given estimated lifetime in real time, as design decisions are taken informed by the resulting data.

\section{Sustainable improvement implementation measures and results}

“(...)Sustainable building design hinges on the ability to gain insight into construction outcomes through analysis, prediction, and optimisation of the design to lower environmental impact through reduced energy consumption, smaller carbon footprint,(...)" (Deutsch, 2011)

The analysis using the measurement unit of $\mathrm{CO} 2$ gives the student a common factor to deal with two different factors that consist of matter and energy, thus keeping in mind that environmental building sustainability is mainly about impact and damage to our planet concerning a building life cycle.
Rapidly, they develop a critical ecological sense towards the "standard" building systems and make conscious decisions.

Depending on the type of building stage chosen, design or existing one, these issues have a totally different impact and approach. Students that are working on the design stage can potentially change all the materials and construction systems, testing from traditional concrete and steel structures to wood and sometimes even rammed earth. The balance between material and energy is crucial and often difficult to achieve. These constraints are very important for the creation of conscious knowledge. The integrated workflow and methodology takes away a part of the complexity and delay when working with different interfaces and software, allowing the student to focus and solve the environmental issues and problems.

The solar analysis creates a huge increment in the awareness of the impact of design decisions on the building's geometry and orientation. It also proved interesting in this case to have exercises on the design and existing stage of different buildings, acting as comparative case studies of various levels of implementation constraints.

Using the initial model as a baseline building, all the comparative energy analyses accompany the upgrades, allowing students to work with data driven design and systems decisions.

The implementation of on-site renewable energy sources gives a very precise perception of the articulation between weather data and on-site energy generation, both by location and by the time of the year.

"These trends show that buildings are becoming more complicated to build. They are taking more resources to construct and operate, and this translates to the increasing lifecycle cost for a building. As these costs and complexities escalate, we are flooded with more information and data to manage the building." (Krygiel, 2008)

To answer the question of whether the new methodology was an effective teaching tool in preparing and giving the correct tools to the students as far as teaching project based sustainable building and construction techniques, learning results from several projects were analysed and two student surveys were carried out. The conclusions of this paper are not static but always evolving, subject to modification based upon research with larger populations and evolution of the tools available.

One important aspect to be considered is the result of the surveys by students that worked with both methods and therefore had a comparative reflection.

The data generated by this research results in a mix of qualitative and quantitative information analysed to form evaluative findings. Data from the survey consists of feedback from the students regarding the methodological effectiveness of using BIM in class and is quantitative.

The performance of the students in the projects as comparative results is qualitative. This provides information for evaluating 
Table 1 Comparison of exercise results

\begin{tabular}{|c|c|c|c|c|c|c|c|c|}
\hline & building stage & area & baseline model & & final design & & improvements & \\
\hline & & & $\begin{array}{l}\text { embodied } \\
\text { carbon } \\
\mathrm{KgCo} 2\end{array}$ & $\begin{array}{l}\text { Emissions - } \\
\text { energy demands } \\
\mathrm{Co} 2 \mathrm{Kg} / \text { year }\end{array}$ & $\begin{array}{l}\text { embodied carbon } \\
\mathrm{KgCo} 2\end{array}$ & $\begin{array}{l}\text { Emissions - } \\
\text { energy demands } \\
\mathrm{Co} 2 \mathrm{Kg} / \text { year }\end{array}$ & $\begin{array}{l}\text { embodied carbon } \\
\mathrm{KgCo} 2\end{array}$ & $\begin{array}{l}\text { Emissions - } \\
\text { energy demands } \\
\mathrm{Co} 2 \mathrm{Kg} / \text { year }\end{array}$ \\
\hline 1 & built & 136 & 48514.43 & 353 & 34934.26 & 117 & $-27.99 \%$ & $-66.86 \%$ \\
\hline 2 & built & 160 & 63075.80 & 430 & 41001.15 & 151 & $-35.00 \%$ & $-64.88 \%$ \\
\hline 3 & built & 205 & 79815.87 & 536 & 50530.72 & 224 & $-36.69 \%$ & $-58.21 \%$ \\
\hline 4 & built & 156 & 62737.39 & 505 & 40552.65 & 200 & $-35.36 \%$ & $-60.40 \%$ \\
\hline 5 & built & 184 & 75997.80 & 581 & 47830.25 & 252 & $-37.06 \%$ & $-56.63 \%$ \\
\hline \multirow[t]{2}{*}{6} & built & 225 & 90932.09 & 852 & 60588.00 & 311 & $-33.37 \%$ & $-63.50 \%$ \\
\hline & average & & & & & & $-34.25 \%$ & $-61.74 \%$ \\
\hline 7 & design & 332.51 & 174387.41 & 2555 & 104607.41 & 105 & $-40.01 \%$ & $-95.89 \%$ \\
\hline 8 & design & 200 & 104891.53 & 1521 & 35827.36 & 223 & $-65.84 \%$ & $-85.34 \%$ \\
\hline 9 & design & 180 & 72745.67 & 1006 & 50247.55 & 221 & $-30.93 \%$ & $-78.03 \%$ \\
\hline 10 & design & 225 & 118002.97 & 1735 & 70693.70 & 350 & $-40.09 \%$ & $-79.83 \%$ \\
\hline 11 & design & 195 & 102300.24 & 1525 & 60267.90 & 400 & $-41.09 \%$ & $-73.77 \%$ \\
\hline \multirow[t]{2}{*}{12} & design & 232 & 151711.05 & 1714 & 71705.60 & 521 & $-52.74 \%$ & $-69.60 \%$ \\
\hline & average & & & & & & $-45.12 \%$ & $-80.41 \%$ \\
\hline
\end{tabular}

student understanding of concepts and design parameters that affect the sustainable overall quality of the building design.

"The benefit of early analysis - even as early as conceptual design - is that it allows the most influence on building performance with the least effort. BIM's adaptability is compatible with performance-driven (sustainable) design. BIM becomes a sustainable design environment, then, as it potentially integrates quantitative analysis in the design decision-making process." (Francois, 2012)

The first survey covered a prior knowledge perception of each student and consisted of questions whose answers were always a. good knowledge, b. some knowledge, c. no knowledge on the six questions. The questions were: 1 . What degree of knowledge do you have on passive architectural design systems? 2. What degree of knowledge do you have on active architectural design systems? 3. What degree of knowledge do you have on the difference between active and passive systems? 4. What degree of knowledge do you have on building energy consumption? 5. What degree of knowledge do you have on building material embodied energy? 6. What degree of knowledge do you have on $\mathrm{CO} 2$ as a holistic sustainability measuring unit? The second survey to conclude the lectures was divided into two parts, the first consisting of the same questions and answers and a second of a new set related to the methodology implemented whose answers were: a. agree, b. disagree, c. neutral to the questions: 7. The BIM methodology used in class helped you better understand passive architectural design systems? 8. The BIM methodology used in class helped you better understand active architectural design systems? 9. The
BIM methodology used in class helped you better understand the difference between active and passive systems? 10. The BIM methodology used in class helped you better understand building energy consumption? 11. The BIM methodology used in class helped you better understand building material embodied energy? 12. The BIM methodology used in class helped you better understand $\mathrm{CO} 2$ as a holistic sustainability measure unit? 13. The BIM methodology used in class helped you better understand the whole building system including architecture design? 14. The BIM methodology of using an actual building and energy consumption data in real time in the project gave me more motivation to do the project? 15 . Without doing the architectural BIM modelling I feel I can learn similar knowledge in other classes.

\section{Conclusion}

The use of BIM and BEM models was a significant advantage in the teaching and implementation of environmentally sound and sustainable building measures, both technically as well as conceptually. It allowed students to acknowledge in a very practical and immediate way the advantages and disadvantages of their designs and building material choices. They were also able to learn how to confront and consider materials from a new perspective.

The average gain in materials embodied carbon for built case studies was $34.25 \%$ in comparison to the $45.12 \%$ for models still in the design stage, while the gain in $\mathrm{CO} 2$ emissions due to energy demands was respectively $61.74 \%$ and $80.41 \%$. We were able to conclude that the most favourable stage for 

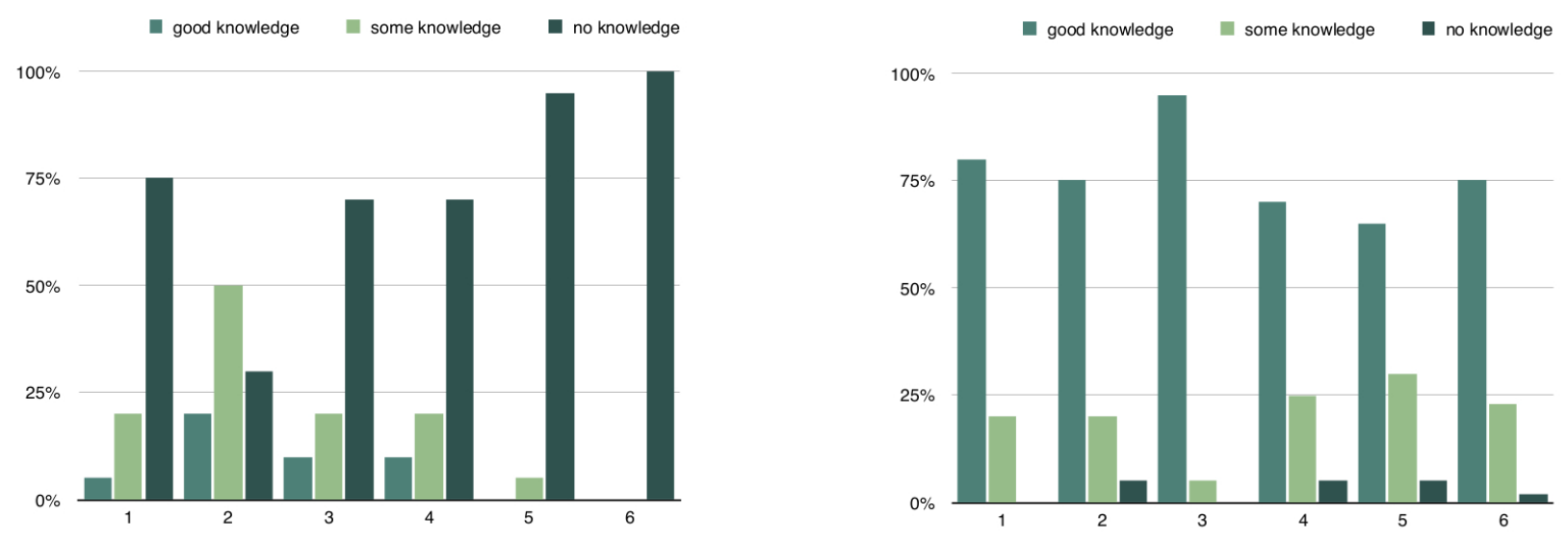

Fig. 4 Comparison of first and final surveys results of questions 1 to 6 (author)

implementing energy and material conscious choices and systems is during the design stage. Despite this, we are also aware that the refurbishment and rehabilitation construction market is very present in the industry, so it should not be neglected.

Figure 4 represents the results of the first and last surveys pointing clearly to the evolution of students' confidence in their knowledge. The entry results are clearly antagonistic to the last ones. In perspective, the conclusion points to a good acquisition of knowledge using the proposed method.

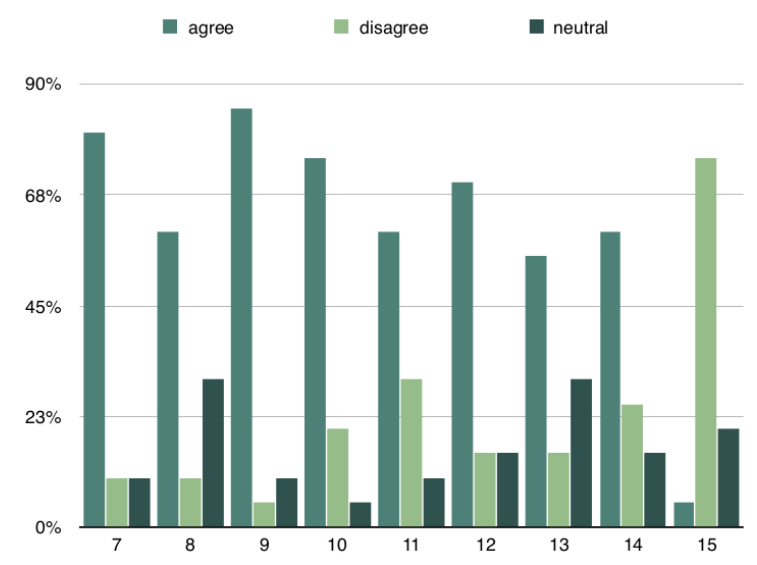

Fig. 5 Final survey results of questions 7 to 15 (author)

The Questions 7 to 15 of the second survey are directly linked to the application of the methodology as well as its future use as an informed design tool by the students.

"Simulation tools are most effective during the early stages of the project, which is when decisions influencing the energy performance of the building have the greatest impact." (Kuslikis, 2011)

A weakness of this exercise is the absolute focus on environmentally conscious material and design choices, neglecting the economic aspect of these decisions, sometimes resulting in more expensive choices in both cases. One example is the choice of cork as an insulator, as it is a local and very ecological material, despite being the most costly. Another weakness is the virtual digital environment that sometimes produces unrealistic results, often very optimistic or awkward, so many times hard to interpret and correct.

“(...) informed building design is one of the least expensive pieces of an overall strategy to minimise energy use and associated climate change. (...) Design simulation can also keep the architect from recommending the wrong strategies." (Anderson, 2014)

As a main conclusion, this method of integrated BIM to BEM proves to be very efficient and engaging. It is a methodological approach that prepares the students both in theory and practice, with a hands-on approach, one that is data driven with the conceptual methodology creating conscious results. The use of $\mathrm{CO} 2$ as a sustainable measuring unit clarifies and simplifies the process of dealing with matter and energy in the early design stages.

\section{References}

Anderson, K. (2014). Design Energy Simulation for Architects - Guide to 3D graphics. Routledge.

Deutsch, R. (2011). BIM and Integrated Design strategies for architectural practice. John Wiley \& Sons, Inc.

Farina, L., Rinaldi, S. (2000). Positive Linear Systems: Theory and Applications. Wiley, New York, NY.

Francois, L. (2012). BIM in small-scale sustainable design. John Wiley \& Sons, Inc.

Krygiel, E., Nies, B. (2008). Green BIM: Successful Sustainable Design with Building Information Modeling. John Wiley \& Sons, Inc.

Kuslikis, V. (2011). BIM in Energy Simulations. CH2MHill.

Lysen, E. H. (1996). The TriasEnergetica:solar energy strategies for developing countries. In: Goetzberger, A., Luther, J. (eds.) Eurosun Conference 1996, DGS Sonnenenergie, Freiburg, Switzerland, pp. 16-19. 